\title{
Export or Not with Productivity Heterogeneous Enterprises? Empirical Evidence from China’s Bio-Pharmaceutical Industry
}

\author{
Zhiying $\mathrm{Ji}^{1}$ \& Jiayi $\mathrm{Ye}^{2}$ \\ ${ }^{1}$ Sydney Institute of Language and Commerce, Shanghai University, Shanghai, China \\ ${ }^{2}$ Industrial and Commercial Bank of China, Shanghai, China \\ Correspondence: Ji Zhiying, Sydney Institute of Language and Commerce, Shanghai University, Shanghai, \\ No.20, Chengzhong Road, Jiading District, Shanghai, China. Tel: 86-21-6998-0028 ext 85081. E-mail: \\ jizhiying@shu.edu.cn
}

Received: February 18, 2013

Accepted: March 7, 2013

Online Published: March 20, 2013

doi:10.5539/ibr.v6n4p164

URL: http://dx.doi.org/10.5539/ibr.v6n4p164

\begin{abstract}
In this paper, the strategy choice of export or not of Chinese biomedical enterprises has been empirically analyzed under the assumption of firm's productivity heterogeneity of new - new trade theory. With the Probit and Tobit model regression analysis on enterprise productivity and export-oriented strategy choice, a positive correlation between the level of productivity and export strategy has been found and the productivity is the key factor in deciding whether to choose the export-oriented strategy or not, and the results of this study do not support the "productivity paradox".
\end{abstract}

Keywords: new-new trade theory, productivity heterogeneity, bio-pharmaceutical industry, productivity paradox

\section{Introduction}

In 1990s, Melitz introduced enterprise heterogeneity to the research of international trade and investment, which is called new-new trade theory based on enterprises heterogeneity. This theory explains how enterprises' trade mode is influenced by heterogeneous factors and institutional factors, and pushes the empirical research of international trade from macro -field to micro-field. Based on the model of Melitz (2003), Helpman \& Yeaple (2004) explored more about heterogeneous firms trade model, and studied the influence of enterprise heterogeneity on strategy choice of export and FDI, and concluded that the productivity difference between enterprises is the main factor influencing the enterprises' strategies. It means that enterprises with low productivity can only serve domestic market, those with higher productivity can choose to export, and with the highest productivity be capable of gaining most profits by building factories overseas.

Based on theoretically heterogeneous firms trade model, many scholars empirically test the relationship between productivity and the strategy choice. For example, Head and Ries (2003) proved that if the enterprises have no cost advantage with FDI in the host countries, they must have a higher productivity than export enterprises. Based on general equilibrium framework, Nocke and Yeaple (2006) analyzed the influences of productivity heterogeneous characteristics on the entry mode to international market, such as export, Greenfield FDI and cross-borde M\&A. The result of the research proved that high productivity is enterprises' advantage and core competitiveness, which can help enterprises to choose different strategy. Chinese scholars have empirical research with domestic sample, and have the different conclusion, which is called "productivity paradox". For example, Tang, Liu (2011)'s research supports the "Paradox of productivity" that export enterprises have lower productivity than non-export enterprises. They expained the possible reason for this may be Chinese enterprises having higher costs to domestic market. Li, C. D. (2010) used enterprise data of 30 manufacturing industries, and found that Chinese export enterprises' average productivity is lower than those domestic-based enterprises, which proved the existence of "Paradox of productivity". Furthermore, the result shows the "Paradox of productivity" more evident in private enterprises, then followed by collective enterprises, and the state-owned enterprises being most insignificant. Based on new-new trade theory with the assumption of enterprise heterogeneity, this article empirically analyzes export strategy decision taking domestic bio-pharmaceutical companies as research sample.

The remainder of this paper is composed of three sections. In section 2, we extend the model of heterogeneous 
enterprises' strategy choice and put forward some basic hypothesis. In section 3, the empirical analysis of strategy choice on the sample of bio-pharmaceutical industry is made. And the last part is the conclusion of this article.

\section{The Extended Model and Basic Assumption of Heterogeneous Firms' Strategy Choice}

Based on the theoretical model by Helpman et al. (2004), this article builds an analyzing framework of enterprise heterogeneity and strategy choice (export or FDI). Assume that heterogeneous firm produces differentiated goods and consumers having the same preferences. So the utility function and consumption function can be described as the follows:

$$
\begin{gathered}
u_{j}=\prod_{s} C_{j s}^{\theta s} \\
C_{j s}=\left[\int_{\omega \in \Omega_{j s}} x_{j s}(\omega)^{\alpha} d \omega\right]^{1 / \alpha}, \alpha \in(0,1)
\end{gathered}
$$

Here, $x_{j s}(\omega)$ is the quantity of consumed products, $\Omega$ represents the quantity of production in industry $\mathrm{s}$, country j. $\alpha$ determines the elasticity of substitution between products (the elasticity of substitution is $\sigma=\frac{1}{1-\alpha}>1$ ). $\theta_{s}$ represents the share of aggregate expenditure in s industry, meanwhile, $\sum_{s} \theta_{s}=1$. Then, the demand for products of $\mathrm{s}$ industry in country $\mathrm{j}$ is:

$$
x_{j s}(\omega)=\frac{Y_{j} \theta_{s} p_{j s}(\omega)^{-\sigma}}{p_{j s}^{1-\sigma}}
$$

Here, $Y_{j}$ represents aggregate expenditure in country j, $p_{j s}(\omega)$ is the price of product $\omega$. We use $P_{j s}$ to represent the price index of s industry in j country, so

$$
P_{j s}=\left[\int_{\omega \in \Omega} p_{j s}(\omega)^{1-\sigma} d \omega\right]^{1 /(1-\sigma)}
$$

Next, we assume that each firm can produce products with labor, and the wage level of country $\mathrm{j}$ is $w_{j}$, the productivity of heterogeneous firm is $\varphi$, which has empirical distribution of $F(\varphi)$ meeting the Pareto optimality, and the shape parameter is $\mathrm{k}$, then:

$$
F(\varphi)=1-\left(\frac{b}{\varphi}\right)^{k}, \quad 0 \leq b \leq \varphi
$$

Here, $\mathrm{b}$ represents the minimum productivity in this industry. We assume $k>1+\sigma$, which ensures the probability of different productivity to be limited distribution. And the variance of Pareto distribution can be described as:

$$
V(\varphi)=\frac{k b^{2}}{(k-2)(k-1)^{2}}, \quad k \in(2,+\infty)
$$

The smaller the parameter $\mathrm{k}$, the bigger the difference in the productivity it represents. We assume that the productivity changes with different industry. When an enterprise chooses to enter the market, it will face the fixed cost of domestic production. The parameter $r$ measures the intra-industrial R\&D density, and $r>1$. An enterprise with a relatively higher $\mathrm{R} \& \mathrm{D}$ density will have a higher $\mathrm{R} \& \mathrm{D}$ cost. If an enterprise chooses to enter foreign markets, it will face the choice between export and FDI. If it chooses to export, it will take extra fixed cost $f^{x}$, domestic wage $w_{h}$ and transportation cost $\tau_{i}>1$. If the enterprise chooses to invest directly in foreign countries, it will take extra fixed cost $f^{I}$, and avoid transportation cost but will face the local labor cost $w_{i}$.

The marginal cost of the enterprise from country h can be represented as:

(1) $c(\varphi)=z w_{h} / \varphi$, when the enterprise sells goods in domestic market;

(2) $c(\varphi)=z w_{h} \tau_{i} / \varphi$, when the enterprise exports its products to country $i$;

(3) $c(\varphi)=z w_{i} / \varphi$, when the enterprise produces its products in country $i$.

According to the demand curve, we can get $p(\varphi)=c(\varphi) / \alpha$, and the profit function in domestic market is:

$$
\pi^{D}=A_{h} \varphi^{\sigma-1}\left(z w_{h}\right)^{1-\sigma}-r f^{D}
$$

In this function, $A_{h}=(1-\alpha) \alpha^{\sigma-1} \theta Y_{h} P_{h}^{\sigma-1}$, which represents the adjusted demand level of country i's industry. $\varphi^{\sigma-1}$ represents productivity exponent, $\sigma \in(1,+\infty)$. When $\pi^{D}=0$, the enterprise's threshold of 
entering domestic market is:

$$
\varphi^{D}=\left(\frac{r f^{D}}{A_{h}\left(z w_{h}\right)^{1-\sigma}}\right)^{1 /(\sigma-1)}
$$

If the enterprise's productivity is smaller than $\varphi^{D}$, it cannot enter this industry. If the enterprise's productivity is bigger than or equal to $\varphi^{D}$, it can enter this industry and sell products. Similarly, the extra profit of export enterprises is:

$$
\pi^{X}=A_{i} \varphi^{\sigma-1}\left(z w_{h} \tau_{i}\right)^{1-\sigma}-f^{X}
$$

When $\pi^{X}=0$, the export enterprise's productivity threshold is:

$$
\varphi^{X}=\left[\frac{f^{X}}{A_{i}\left(z w_{h} \tau_{i}\right)^{1-\sigma}}\right]^{1 /(\sigma-1)}
$$

The extra profit of the enterprises investing in the foreign markets is:

$$
\pi^{I}=A_{i} \varphi^{\sigma-1}\left(z w_{i}\right)^{1-\sigma}-f^{I}
$$

Taking $\pi^{I}=0$, the productivity threshold of FDI enterprise is:

$$
\varphi^{I}=\left[\frac{f^{I}-f^{x}}{A_{i} z^{1-\sigma}\left[w_{i}^{1-\sigma}-\left(w_{h} \tau_{i}\right)^{1-\sigma}\right]}\right]^{1 /(\sigma-1)}
$$

From the threshold we find that FDI strategy requiring the highest productivity, followed by export-oriented strategy, enterprises with lower productivity can only serve in domestic market, and the enterprise with the lowest productivity will exit from the market.

According to the theoretical model, the quantity of enterprises in the market and its productivity can be derived, thus we'll get the related hypothesis. According to the Pareto optimality assumption, the quantity of enterprises producing and selling goods in domestic market is:

$$
\delta^{D}=\frac{F\left(\varphi^{x}\right)-F\left(\varphi^{D}\right)}{1-F\left(\varphi^{D}\right)}=1-\left(\varphi^{D} / \varphi^{x}\right)^{k}
$$

The sum of export-oriented enterprises and FDI enterprises is:

$$
\delta^{N}=\frac{1-F\left(\varphi^{X}\right)}{1-F\left(\varphi^{D}\right)}=\left(\varphi^{D} / \varphi^{X}\right)^{k}
$$

And the quantity of FDI enterprises is:

$$
\delta^{I}=\frac{1-F\left(\varphi^{I}\right)}{1-F\left(\varphi^{D}\right)}=\left(\varphi^{D} / \varphi^{I}\right)^{k}
$$

Thus the quantity of export-oriented enterprises is:

$$
\delta^{X}=\delta^{N}-\delta^{I}=\left(\varphi^{D} / \varphi^{X}\right)^{k}-\left(\varphi^{D} / \varphi^{I}\right)^{k}
$$

As the $k$ has a relatively insignificant impact on $\delta^{x}$, we use the percentage of export-oriented enterprises to FDI enterprises to study the effect of productivity: $\delta^{X I}=\delta^{X} / \delta^{I}=\left(\varphi^{I} / \varphi^{X}\right)^{k}-1, \quad \delta^{X I}$ will increase with $k$ increasing.

According to the analysis above, when $A_{h}=A$, we assume that $r f^{D}<\tau_{i}^{\sigma-1} f^{X}<\left(w_{i} / w_{h}\right)^{\sigma-1} f^{I}$, then $\phi^{p}<\phi^{X}<\phi$, which means the optimal choice of enterprise's international strategy depends on the enterprise's productivity. As a result, the following hypotheses are made:

Hypothesis 1: When $\varphi^{D}<\varphi<\varphi^{x}$, the enterprise neither exports nor invests in the foreign markets directly, it only produce and sale its products in domestic market.

Hypothesis 2: When $\varphi^{x}<\varphi<\varphi^{I}$, the enterprise not only sales products in domestic market, but also exports its products to foreign market.

Hypothesis 3: When $\varphi>\varphi^{I}$, the enterprise invests in the foreign markets directly.

\section{Empirical Analysis on Export Strategy Choice of Productivity Heterogeneous Firms}

\subsection{Sample and Data}

This article chooses 10 Chinese listed companies in China's bio-pharmaceutical industry. These companies are located in different regions with different business, as the typical of this industry. The time span is from 2006 to 2010. All the data is from the annual reports of companies and transformed to the prices in 2006. 


\subsection{Estimation of Heterogeneous Productivity with SFA}

SFA is first proposed by Aigner et al. (1977) and Meeusen and Van den Broek (1977), then Battese and Coelli (1992) improved this method by using panel data. In this article we choose the following Translog Production Function to estimate enterprises' productivity:

$$
\begin{gathered}
y_{i t}=\beta_{0}+\sum_{j} \beta_{j} x_{j i t}+\frac{1}{2} \sum_{j} \sum_{h} \beta_{j h} x_{j i t} x_{h i t}+\varepsilon_{i t} \\
\varepsilon_{i t}=v_{i t}-u_{i t}
\end{gathered}
$$

Here, $j, h=t, k, l \cdot u_{i t}$ is nonnegative, and obeys truncated normal distribution $\left(u_{i t} \sim N\left[\delta_{0}+\sum_{n=1}^{N} \delta_{n} z_{n i t}, \sigma_{u}^{2}\right]\right), u_{i t}$ represents technology inefficiency; $v_{i t}$ is white noise, and obeys normal distribution of $N\left(0, \sigma_{v}^{2}\right) ; z_{n i t}$ is the factor influencing efficiency. If $\delta_{n}<0$, then $z_{n i t}$ has negative relationship with the inefficiency $u_{i t}$, and has a positive effect on the efficiency level. Conversely, if $\delta_{n}>0$, then $z_{n i t}$ brings inefficiency. $y_{i t}$ represents the logarithm of actual output of enterprise $\mathrm{i}(\mathrm{i}=1,2, \ldots, \mathrm{N})$ at time $\mathrm{t}(\mathrm{t}=1,2, \ldots, \mathrm{T}) . \quad x_{j i t}$ is the logarithm on $\mathrm{jth}$ actual input of individual i in time $t$, includes capital and labor. Using the software of Frontier4.1 to estimate the production function by OLS and MLE respectively, the results are showed in Table 1.

Table 1. Firm's productivity estimation based on stochastic frontier analysis

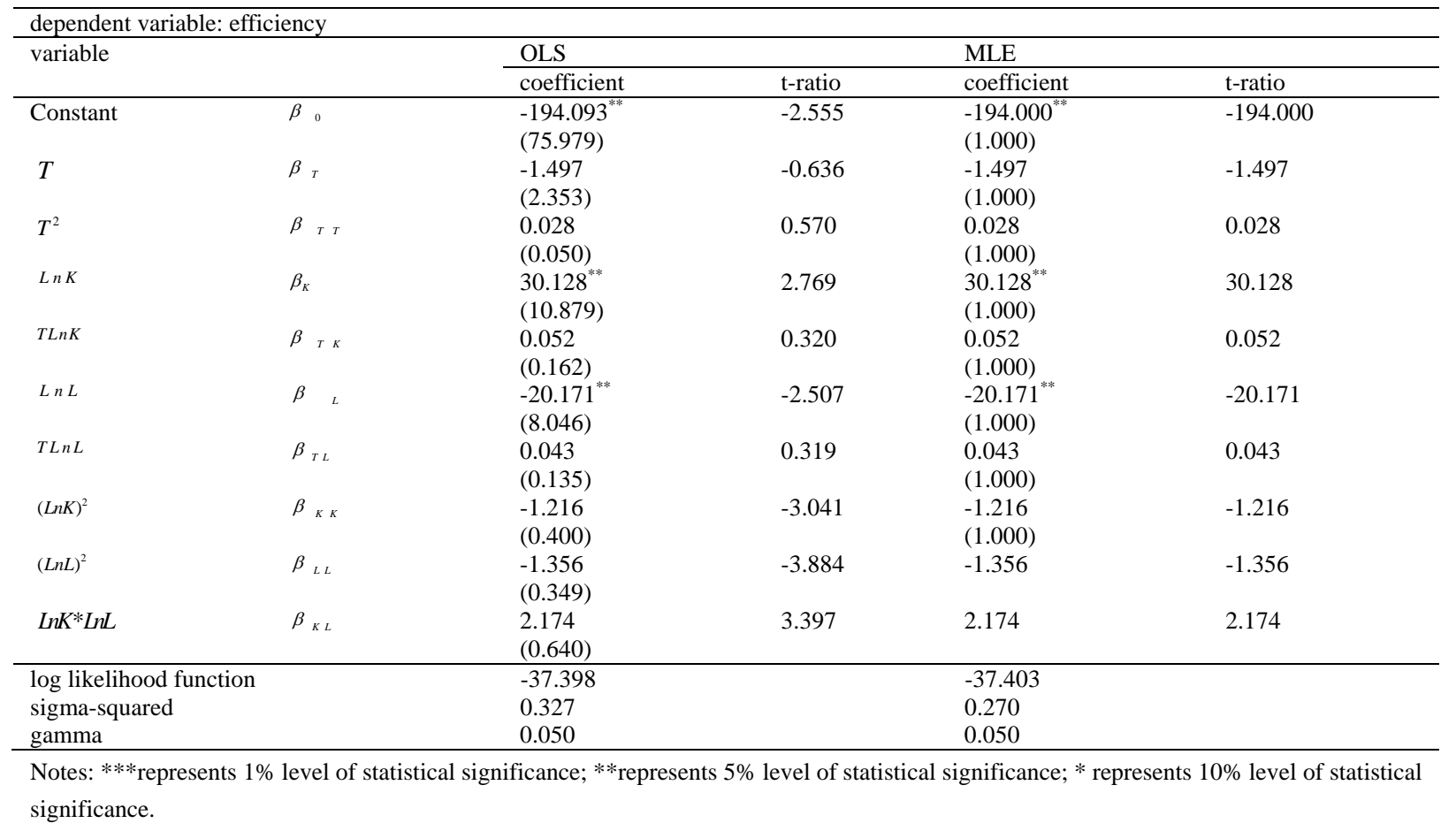

The results in table 1 show that the variables $\mathrm{T}, \mathrm{T}^{2}$, TLnK, TLnL are not statistically significant, which means that enterprises' output increasing mainly comes from factor input and the improvement in efficiency, the production frontier is unchanged.

With the MLE results and stochastic frontier production function, we can get the individual productivity for each enterprise, which is showed in Table 2. The productivity is influenced by the external economic environment. Under the financial crisis from 2008 to 2009, bio-pharmaceutical enterprises' productivity has a significant decrease. However, there are significant differences between enterprises, which is the enterprises' productivity endogeneity. Whether the enterprises' productivity has significant impact on its strategy choice or not? Whether "paradox of productivity" exists in China's bio-pharmaceutical industry? These questions will be tested further in the following part. 
Table 2. The productivity of biological medicine company from 2006 to 2010

\begin{tabular}{lllllllll}
\hline company & year & TFP & company & year & TFP & company & year & TFP \\
\hline 1 & 1 & 0.9069 & 8 & 2 & 0.9108 & 5 & 4 & 0.9109 \\
2 & 1 & 0.9119 & 9 & 2 & 0.9264 & 6 & 4 & 0.9062 \\
3 & 1 & 0.9126 & 10 & 2 & 0.9263 & 7 & 4 & 0.9106 \\
4 & 1 & 0.9168 & 1 & 3 & 0.9183 & 8 & 4 & 0.9172 \\
5 & 1 & 0.9022 & 2 & 3 & 0.9113 & 9 & 4 & 0.9223 \\
6 & 1 & 0.9106 & 3 & 3 & 0.8951 & 10 & 4 & 0.9294 \\
7 & 1 & 0.9194 & 4 & 3 & 0.9143 & 1 & 5 & 0.9055 \\
8 & 1 & 0.9115 & 5 & 3 & 0.9141 & 2 & 5 & 0.9100 \\
9 & 1 & 0.9232 & 6 & 3 & 0.9075 & 3 & 5 & 0.8914 \\
10 & 1 & 0.9208 & 7 & 3 & 0.9151 & 4 & 5 & 0.9234 \\
1 & 2 & 0.9086 & 8 & 3 & 0.9169 & 5 & 5 & 0.9147 \\
2 & 2 & 0.9115 & 9 & 3 & 0.9223 & 6 & 5 & 0.9070 \\
3 & 2 & 0.9020 & 10 & 3 & 0.9269 & 7 & 5 & 0.9124 \\
4 & 2 & 0.9152 & 1 & 4 & 0.9098 & 8 & 5 & 0.9135 \\
5 & 2 & 0.9099 & 2 & 4 & 0.9061 & 9 & 5 & 0.9286 \\
6 & 2 & 0.9156 & 3 & 4 & 0.8999 & 10 & 5 & 0.9310 \\
7 & 2 & 0.9164 & 4 & 4 & 0.9131 & & & 5 \\
\hline
\end{tabular}

\subsection{Empirical Analysis on the Export Strategy Choice of Productivity Heterogeneous Firms}

According to the theoretical deduction and basic hypothesis, heterogeneous firms' strategy has relationship with labor, capital and R\&D as well as productivity. So we set the following Probit model to test the hypothesis:

$$
\delta_{i, t}=\beta_{0}+\beta_{1} T f p_{i, t}+\beta_{2} E m p_{i, t}+\beta_{3} C a p_{i, t}+\beta_{4} R D_{i, t}+\beta_{5} S a l_{i, t}+\mu_{i, t}
$$

Here, $\delta_{i, t}$ is a dummy variable, which represents bio-pharmaceutical enterprises' strategy, $\delta_{i, t}=1$ is export-oriented strategy at time t, and $\delta_{i, t}=0$ is only serving the domestic market at time t. $T f p_{i, t}$ is the enterprise's TFP. Furthermore, we choose enterprises' labor input $E m p_{i, t}$, Paid-in Capital $C_{a p} p_{i, t}, \mathrm{R} \& \mathrm{D} R D_{i, t}$ and the business revenue $\mathrm{Sal}_{i, t}$ as the control variables. All the data comes from companies' annual reports, and the estimated results are showed in table 3.

Table 3. The results of Probit model estimation on strategy choice of bio-pharmaceutical companies

\begin{tabular}{llll}
\hline \multicolumn{2}{l}{ dependent variable: choice of strategy } & & \\
\hline variable & coefficient & standard-error & z-ratio \\
\hline constant & 0.2302 & 0.0432 & 5.33 \\
Emp & 0.0196 & 0.0012 & 16.03 \\
Cap & 0.0038 & 0.0011 & 3.37 \\
RD & -0.0005 & 0.0005 & -0.89 \\
Sal & 0.0111 & 0.0008 & 14.63 \\
Tfp & 0.1432 & 0.0481 & 2.97 \\
log likelihood & 166.650 & & \\
\hline
\end{tabular}

According to the Probit regression results, the variables are statistically significant, and the reliability and stability of the model are also very good. The variable of productivity has a significant influence on export-oriented strategy choice.

The Probit model can be expressed as:

$$
\delta_{i, t}=0.2302+0.1432 \operatorname{Tfp}_{i, t}+0.0196 \mathrm{Emp}_{i, t}+0.0038 \operatorname{Cap}_{i, t}-0.0005 R D_{i, t}+0.0111 \mathrm{Sal}_{i, t}
$$

So the probability of choosing export-oriented strategy for bio-pharmaceutical enterprises is:

$$
p_{i}=\phi\left(\delta_{i, t}\right)=\phi\left(0.1432 T f p_{i, t}+0.0196 E m p_{i, t}+0.0038 \text { Cap }_{i, t}-0.0005 R D_{i, t}+0.0111 \mathrm{Sal}_{i, t}\right)
$$

From this probability function, the enterprises with higher productivity are more likely to choose export-oriented strategy. The control variables of labor input, capital, and business revenue are also improve the probability of China's bio-pharmaceutical enterprises choosing export-oriented strategy. In all, the results prove the basic hypothesis of new-new trade theory, and we will also use Tobit model to do the robust test, the results are showed in table4. 
Table 4. The results of Tobit robust test

\begin{tabular}{llll}
\hline \multicolumn{2}{l}{ dependent variable: choice of strategy } & & \\
\hline variable & coefficient & standard-error & z-ratio \\
\hline constant & 0.1948 & 0.0409 & 4.68 \\
Emp & 0.0141 & 0.0015 & 10.32 \\
Cap & 0.0013 & 0.0045 & 2.54 \\
RD & -0.0015 & 0.0128 & -0.91 \\
Sal & 0.0115 & 0.0027 & 13.02 \\
Tfp & 0.3276 & 0.0401 & 2.80 \\
\hline
\end{tabular}

The Tobit model can be expressed as:

$$
\delta_{i, t}=0.1948+0.3276 T f p+0.0141 E m p+0.0013 \text { Cap }-0.0015 R D+0.0115 \text { Sal }
$$

Similar results we get by using the Tobit model. That means the sign of different variable is not affected by the model and we conclude that results are robust.

\section{Conclusions}

In this article we use SFA method to calculate the TFP of bio-pharmaceutical listed companies, the results show that there is significant difference between enterprises' productivity. According to the new-new trade theory, productivity heterogeneous enterprises will have different strategy of export or FDI. We use Probit and Tobit models to identify the relationship between the enterprises' productivity and the choice of export strategy, the results show that enterprises' productivity has a significantly positive relationship with export strategy, and the productivity becomes the key factor determining whether the enterprise choose export strategy or not. The results of this article don't support the "Parodox of productivity". As bio-pharmaceutical enterprises mainly engage in knowledge-intensive processing trade rather than labor-intensive processing trade, "Parodox of productivity" is not the general conclusion to all Chinese manufacturing sectors. In China there is relatively high cost in entering domestic market and the processing trade occupies almost half of China's foreign trade. It does not contradictory to the new-new trade theory of productivity determining enterprises' strategy.

Our research reveals that: (1) Productivity is an important factor determining China's bio-pharmaceutical enterprises' internationalization strategy. (2) Reduce the cost of entering domestic market, strengthen enterprises in home market, and help them get out of the development mode of low factor cost- low value added- low profit, thus improve their status in the global value chain. (3) From the policy perspective, reducing the market barriers, improving factor mobility and providing innovative environment are the basis and assurance of the overall improvement of Chinese manufacturing sector.

\section{References}

Battese, G. E., \& Coelli, T. J. (1992). Frontier Production Functions, Technical Efficiency and Panel Data: With Application to Paddy Farmers in India. Journal of Productivity Analysis, 3, 153-169. http://dx.doi.org/10.1007/BF00158774

Head, K., \& Ries, J. (2003). Heterogeneity and the FDI versus export decision of Japanese manufacturers. Journal of the Japanese and International Economies, 17, 448-467. http://dx.doi.org/10.1016/j.jjie.2003.09.003

Helpman, Melitz, \& Yeaple. (2004). Exports vs. FDI with Heterogeneous Firms. American Economic Review, 94, 300-316. http://dx.doi.org/10.1257/000282804322970814

Hong, L. Y., \& Luo, N. S. (2007). The development path and strategy selection of enterprises internationalization in a new pattern of global production and trade - the productivity heterogeneity theory-based analysis method. World economic research, 12, 55-61.

Li, C. D. (2010). Whether there is a "paradox" in Chinese export enterprises: the test on the data of Chinese manufacturing enterprises. World economics, 7, 64-81.

Li, C. D., \& Yin, X. S. (2009). China’s export enterprises ‘productivity paradox' and its interpretation. Financial and Economics. Finance \& Trade Economics, 11, 84-90.

Melitz. (2003). The Impact of Trade on Intra-Industry Reallocations and Aggregate Industry Productivity. Econometrics, 71, 1695-1725. http://dx.doi.org/10.1111/1468-0262.00467

Nocke, V., \& Yeaple, S. (2006). Globalization and Endogenous Firm Scope. NBER Working Papers 12322, National Bureau of Economic Research, Inc. 